\title{
História escolar e ensino de História na escolarização básica brasileira: Refletindo sobre percursos históricos, contextos e discussões
}

School history and History teaching in Brazilian basic schooling: Reflecting on historical courses, contexts and discussions

Historia escolar e enseñanza de Historia en la escuela básica brasileña: Reflexión sobre cursos históricos, contextos y discusiones

Recebido: 18/06/2021 | Revisado: 23/06/2021 | Aceito: 24/06/2021 | Publicado: 10/07/2021

\author{
Ricardo Jose Lima Bezerra \\ ORCID: https://orcid.org/0000-0002-7281-6063 \\ Universidade de Pernambuco, Brasil \\ E-mail: ricardo.bezerra@upe.br
}

\begin{abstract}
Resumo
A História Escolar e o Ensino de História percorrem uma trajetória de encontros, e desencontros, avanços e inflexões, refletindo a dinâmica e complexa realidade escolar brasileira, desde o período colonial até o final da década de 1990. Neste texto, descrevemos e refletimos, a partir de uma abordagem metodológica da pesquisa bibliográfica e documental, sobre esta trajetória, confrontando com aspectos da política e da legislação escolar em diferentes períodos históricos. Concluímos que, ao refletir sobre esses aspectos e itinerários do Ensino de História e a História Escolar, torna-se possível contribuir para a compreensão sobre os processos de ensino e aprendizagem e de formação da consciência histórica das pessoas e dos grupos sociais no contexto da escolarização brasileira, e, humildemente, contribuir também para o incremento do debate e das pesquisas sobre esta temática.
\end{abstract}

Palavras-chave: Ensino; História do ensino de história; Escolarização brasileira; História na escola; História da educação.

\begin{abstract}
School History and the Teaching of History follow a trajectory of encounters, and disagreements, advances and inflections, reflecting the dynamic and complex Brazilian school reality, from the colonial period to the end of the 1990s. From a methodological approach of bibliographic and documentary research, we describe and reflect on this trajectory, confronting aspects of school policy and legislation in different historical periods. We conclude that, by reflecting on these aspects and itineraries of the Teaching of History and School History, it becomes possible to contribute to the understanding of the processes of teaching and learning and the formation of the historical awareness of people and social groups in the context of schooling Brazilian, and, humbly, also contribute to the increase of debate and research on this theme.
\end{abstract}

Keywords: Teaching; History of history teaching; Brazilian schooling; History at school; History of education.

\section{Resumen}

La Historia Escolar y la Enseñanza de la Historia siguen una trayectoria de encuentros, y desacuerdos, avances e inflexiones, reflejando la dinámica y compleja realidad escolar brasileña, desde el período colonial hasta fines de la década de 1990. En estos escritos, desde un enfoque metodológico de investigación bibliográfica y documental, describimos y reflexionamos en esta trayectoria, confrontando aspectos de la política y legislación escolar en diferentes períodos históricos. Concluimos que, al reflexionar sobre estos aspectos e itinerarios de la Didáctica de la Historia y la Historia Escolar, se hace posible contribuir a la comprensión de los procesos de enseñanza y aprendizaje y a la formación de la conciencia histórica de las personas y grupos sociales en el contexto de la escolarización y, humildemente, también contribuir al aumento del debate y la investigación sobre este tema.

Palabras clave: Enseñanza; Historia de la enseñanza de la historia; Escolaridad brasileña; Historia en la escuela; Historia de la educación. 


\section{Introdução}

A área do conhecimento que estuda a humanidade no tempo e no espaço e que, através dela, busca-se entender e compreender os acontecimentos e os processos do presente a partir da relação deste com o passado convencionou-se chamarmos de História. Esta, por sua vez, busca apresentar, explicar, interpretar e compreender as ações e atuações dos indivíduos e das sociedades contextualizada pela realidade em que estes se encontram. Mediada por documentos e técnicas de pesquisa, o historiador é um construtor de mundos fragmentados, um artífice dos tempos e espaços a partir do que é possível vislumbrar destes tempos idos ou não tão remotos assim. Peter Burke nos diz que (2012, p.12), a História pode ser definida "como o estudo de sociedades humanas no plural, destacando as diferenças entre elas e as mudanças ocorridas em cada uma como o passar do tempo". A História (essa, que em geral encontramos com a letra "h" maiúscula), nos apresenta os indivíduos e grupos sociais em suas relações entre si, bem como o desenvolvimento, as transformações e as permanências vividas de um dado período em suas diferenciações e semelhanças com os demais.

Por sua vez, o ensino de História procura abordar, interpretar, apresentar e discutir essa relação entre indivíduos e sociedades em diferentes temporalidades no ambiente e sob o enfoque das práticas e especificidades didático-curriculares, recriando a História campo de conhecimento e pesquisa acadêmica em História escolar, História a ser ensinada/aprendida/apreendida/reelaborada na educação escolar. A História escolar é uma seleção, um recorte temporal e histórico de temáticas, personagens, fatos, processos e contextos, os quais integram o ser humano em diferentes temporalidades, levando para a escola um conjunto de saberes e conhecimentos a serem ensinados, reelaborados na relação com os educandos e avaliados, que criam e recriam o campo específico de conhecimentos num incessante reelaborar, buscando ampliar e desenvolver a consciência histórica dos estudantes em relação com essa reelaboração disciplinar.

Assim, a História escolar na educação básica, se faz essencial na formação da criança e do adolescente. Quando o professor de História reconhece a importância do ensino desse campo disciplinar e exercita a reflexão sobre o papel formativo do ensino de História na construção da consciência histórica dos indivíduos, contribui para a constituição de indivíduos sociais participativos, críticos e responsáveis diante de seus direitos e deveres. A presença da História nos currículos escolares brasileiros afirma-se, dessa forma, pela necessidade de construção de uma sociedade mais reflexiva, mais humana e mais solidária, em face das diversidades e diferenças sociais, étnicas, etárias, de gêneros e regionais do nosso país, como também em favor da mobilização e da ação combativa às desigualdades, às injustiças sociais e aos preconceitos de toda ordem.

\section{Metodologia}

Neste trabalho objetivamos contribuir para ampliar e estimular o debate sobre o Ensino de História, a História Escolar e como essa dinâmica e relação foi experienciada ao longo do percurso construído pela escolarização básica brasileira desde a colônia até o final do século XX.

Para a produção deste artigo foi utilizado o tipo de pesquisa exploratória-explicativa e o método adotado foi o da revisão bibliográfica, com base em um amplo conjunto de obras relacionadas a discussão multi e interdisciplinar sobre Ensino de História no Brasil e a produção historiográfica a respeito do ensino desta componente curricular na educação básica brasileira.

O trabalho aqui empreendido busca, ao mesmo tempo que descreve a História escolar enquanto disciplina do currículo na escolarização brasileira desde a colônia, discutir o Ensino de História e seus matizes temporais, fomentando a pesquisa para melhor (re)conhecer a realidade da educação brasileira. Dessa forma, então, na construção do presente artigo acadêmico lançamos mão de uma pesquisa revisionista da produção bibliográfica, fundamentando-se nos procedimentos oriundos da pesquisa qualitativa, de caráter exploratória. Filiamo-nos a prática crescente na pesquisa educacional ao 
proceder pela opção em pesquisa qualitativa, visto que, como nos informa Lüdke e André (2013) "é cada vez mais evidente o interesse que os pesquisadores da área de educação vê demonstrando pelo uso das metodologias qualitativas.

Para Marconi e Lakatos (2019, p. 269) a pesquisa qualitativa "fornece análise mais detalhada sobre investigações, hábitos, atitudes e tendências de comportamentos”, neste caso expressa na profícua produção bibliográfica sobre as temáticas aqui abordadas.

Assim, qualitativamente objetivou-se entender não só as questões de caráter mais geral sobre o ensino de História, mas também sobre aspectos legais, contextos históricos em diferentes períodos, assim como a reflexão a partir da interpretação de diferentes autores e autoras sobre a temática em tela relacionado à discussão sobre a trajetória da escolarização brasileira ao longo dos últimos 500 anos.

Estes pressupostos nortearam a busca de conceitos, interpretações e informações indispensáveis para a real compreensão do tema abordado. Com base nestes princípios metodológicos foi possível realizar de forma adequada o levantamento, a leitura e a interpretação das ideias e dos dados obtidos. Sobre este método de pesquisa, Severino (2016, p. 131) pontua que:

A pesquisa bibliográfica é aquela que se realiza a partir do registro disponível, decorrente de pesquisas anteriores, em documentos impressos, como livros, artigos, teses etc. Utiliza-se de dados ou de categorias teóricas já trabalhados por outros pesquisadores e devidamente registrados. Os textos tornam-se fontes dos temas a serem pesquisados. O pesquisador trabalha a partir das contribuições dos autores dos estudos analíticos constantes dos textos.

Dessa forma, foi desenvolvida, inicialmente, uma pesquisa com levantamento exploratório para a compreensão dos aspectos teóricos pertinentes à temática investigada. O desenvolvimento desta pesquisa, objetivando a produção deste artigo procedeu pela apropriação de diferentes ideias encontradas em referências bibliográficas consagradas, assim como daquelas contribuições fornecidas por publicações mais recentes e menos conhecidas.

Sobre a pesquisa exploratória, Severino (2016, p. 91):

A pesquisa exploratória busca apenas levantar informações sobre um determinado objeto, delimitando assim um campo de trabalho, mapeando as condições de manifestação desse objeto. Na verdade, ela é uma preparação para a pesquisa explicativa.

Após as primeiras sínteses, com base nas referênicas utilizadas, e no levantamento das informações fornecidas pela pesquisa exploratória, foram articulados os conceitos e as constatações principais, passando-se em seguida, para a escrita do presente artigo acadêmico.

Segundo Lakatos e Marconi (2019, p. 186) a pesquisa bibliográfica ainda se vale de:

[...] publicações avulsas, boletins, jornais, revistas livros, pesquisas monográficas, teses, material cartográfico etc., até meios de comunicação orais: rádio, gravações em fita magnética e audiovisuais: filmes e televisão. Sua finalidade é colocar o pesquisador em contato direto com tudo o que foi escrito, dito ou filmado sobre determinado assunto, inclusive conferências seguidas de debates que tenham sido transcritos por alguma forma, querem publicadas, quer gravadas.

Assim esta pesquisa fez uso de múltiplos textos científicos e acadêmicos para elaborar este artigo a partir de uma reflexão concreta com o intuito de chegar a um resultado satisfatório e coerente na discussão sobre História Escolar e Ensino de História.

Para Severino (2016, p. 132), "a pesquisa exploratória busca apenas levantar informações sobre um determinado objeto, delimitando assim um campo de trabalho, mapeando as condições de manifestação desse objeto". 
Dessa forma, a revisão bibliográfica foi essencial para o desenvolvimento do tema do trabalho, que envolveu a descrição dos aspectos desta produção. Foi utilizada a pesquisa exploratória-explicativa, que para Severino (2016, p. 132) significa que:

A pesquisa exploratória-explicativa é aquela que, além de registrar e analisar os fenômenos estudados, busca identificar suas causas, seja através da aplicação do método experimental/matemático, seja através de interpretação possibilitada pelos métodos qualitativos [como o bibliográfico].

Em síntese, os objetivos apresentados puderam ser atingidos através da pesquisa bibliográfica apresentados, onde foi possível estudar a temática em questão e por meio de análise exploratório-explicativo pode se produzir este artigo empreendendo discussão atinente ao objetivo de ampliar e contribuir para o incremento do debate sobre o Ensino de História na escolarização básica brasileira.

\section{A História da Legislação e da Estrutura da Educação Brasileira: Da Colônia aos Anos 1990.}

\subsection{A educação escolar no período colonial}

Com a criação do Governo Geral em 1548, a dinâmica da colonização sofre algumas mudanças. Porém, nada muito grandioso, as capitanias hereditárias continuariam, pois a criação dessa nova Regulamentação tinha o objetivo de complementar à administração colonial, não substituir o sistema anterior.

No intuito de proteger o território americano pertencente a Portugal, o governo lusitano descarta os planos de uma colonização por meio da ocupação e opta por uma colonização através do povoamento. É nessa conjuntura que em 29 de março de 1549, desembarcava onde hoje é o estado da Bahia, o primeiro governador geral da então colônia portuguesa. Seu nome era Tomé de Sousa e fora nomeado em sete de janeiro daquele mesmo ano. A sua função consistia em "ajudar os pedidos formulados e incentivar a agricultura", principalmente a da cana-de-açúcar, segundo Guilherme de Andrea Frota em sua obra História do Brasil-Colônia.

Juntamente do mais novo - e primeiro-governador do Brasil-Colônia desembarcou também, sob os cargos de Capitão-mor da costa, Provedor-mor da Fazenda e Ouvidor-geral, respectivamente, Pero Góis, Antônio Cardoso de Barros e Pero Borges. Colonos, soldados, degradados e operários, dirigidos por Luís Dias, da mesma forma, compuseram o elenco desta nova empreitada que seria a intensificação do povoamento da América lusitana. Quem também fez parte deste marco foi o padre Manoel da Nóbrega e mais seis jesuítas a qual o primeiro deveria liderar.

"Entre as diretrizes básicas constantes no Regimento, isto é, na nova política ditada por D. João III (17-12-1548), é encontrada um referente à fé católica pela catequese e pela instrução." (Ribeiro, 1998, P. 18). Segundo Luiz A. de Mattos, este Regimento vai ser determinante nesta empreitada colonizadora, pois é a partir da conversão do indígena nas crenças e valores cristãos da sociedade europeia da época que "a colonização portuguesa poderia lançar raízes definitivas".

Assim, Maria Luisa Santos Ribeiro (1998. p. 18) percebe que “(...) por esses poucos fatos, que a organização escolar no Brasil-Colônia está, como não poderia deixar de ser, estreitamente vinculada à política colonizadora dos portugueses.”

Ou seja, a educação escolar no período colonial limitava-se as ordens e vontades da Metrópole portuguesa, que interessada em aumentar suas riquezas e condicionadas pelos valores cristãos da época, visavam tirar da terra todas as matérias-primas e metais preciosos possíveis ao mesmo tempo em que tentavam acreditar estar fazendo o favor de "salvar" os povos nativos (verdadeiros donos da terra) lhes apresentando a fé cristã e os civilizando. "À primeira reação de espanto e temor seguiram-se a necessidade e a vontade de dominar pela fé, o lucro e o poder político." (Wehling, Wehling, 1994 p. 49).

José Carlos Reis também faz um breve comentário a cerca desse europeu ambicioso e colonizador do século XVI. Ele destaca sua visão acerca da sede do europeu em descobrir novos mundos e como ele usa da ideia de "salvar a 
humanidade" como justificativa da falta de sensibilidade ao desconsiderar as crenças e a cultura dos povos conquistados e aniquilar uma boa parte destes. Reis (2006. p. 23) diz o seguinte:

A conquista do mundo não significava necessariamente a perda da alma e a aceitação do diabo, mas a colaboração dos homens na restauração da criação divina. Os europeus retomam a lógica imperialista dos romano-cristãos e se sentem a serviço da salvação da humanidade quando vencem e submetem os pagãos não europeus do mundo inteiro.

Antes da criação do Governo Geral (1548), o clero não tinha uma participação tão ativa nas atividades de colonização, como irá desempenhar a partir desse marco. No primeiro momento, os sacerdotes que aqui chegavam junto às primeiras expedições, estavam muito mais dispostos a atender os seus próprios interesses que aos da Igreja. Agora, eles estavam incumbidos não apenas educar e catequisar os índios, como também os filhos dos colonos portugueses. "Os jesuítas iniciaram a catequese e o processo educativo com o colégio de Salvador.” (Frota, 2000. P. 61).

Anteriormente a chegada dos portugueses, as crianças indígenas não tinham uma educação nos moldes tal qual lhe será apresentada, de forma sistematizada e usando de recursos didáticos como a música, dança e o teatro, como irá ressaltar Anna Cecília Sobral Bezerra (2000, p. 13) em sua monografia (De Uma Escola 'Para o Índio' Para Uma Escola Indígena: Ideias Sobre A Educação Escolar Indígena Na História Do Brasil).

Além de utilizar o canto, a dança e o teatro a educação dos indígenas, os Jesuítas organizavam as reduções, aldeamentos que reuniam uma grande diversidade de povos com culturas diferentes, é válido enfatizar que para os filhos de Loyola, os nativos eram genéricos, não tinham diferenças culturais entre si.

E segundo Ribeiro (1998), completando esta informação, a execução de tarefas do dia a dia na tribo, era suficiente para capacitar a criança indígena a vida adulta naquela comunidade, antes da chegada dos jesuítas as terras americanas.

Quando Tomé de Sousa chega ao Brasil-Colônia passa a reforçar a defesa da mesma contra as ações inimigas, estimula o reconhecimento do interior e favorece o trabalho de catequese e ensino que será realizado, como já dito antes, pelos jesuítas. Com o passar do tempo começou a existir aldeias formadas por indígenas cristianizados, com população "dez ou quinze vezes superior à de cidades ou vilas portuguesas".

A educação da colônia portuguesa irá ser dividida em dois grupos: a destinada aos filhos dos colonos (mesmo estes, eram número de pessoas limitadas) e aquela educação destinada aos indígenas. Esta era organizada em escolas simples, tendo como por objetivo apenas ler e escrever e catequiza-los, afim de "civilizá-los". Enquanto as escolas que seriam para a formação dos filhos dos colonos eram, segundo Bezerra (2000), divididas em dois estilos: "a primeira de formação em ciências clássicas e as de formação sacerdotal”. As Ciências Clássicas para quem tinha como pretensão cursos de Direito, Medicina ou Filosofia, e Sacerdotal, como o próprio nome sugere, era destinada ao preparo de novos membros da instituição religiosa.

Os padres jesuítas também se dedicaram a aprender a língua nativa, para que eles pudessem ser mais bem compreendidos no momento dos ensinamentos cristãos.

Na escola, além de ensinar o catecismo, ensinava-se o português, de forma que a medida que o missionário ensinava, também aprendia o idioma indígena, o que facilitava o relacionamento com a população circundante”. (Bezerra, 2000, p. 14)

Quase sempre esses ensinamentos eram voltados para a criança indígena, que tinha um papel muito importante nessa missão e servia de mediadores desses novos ensinamentos para os seus pais. Outra característica própria desse período jesuítico e que foi fundamental na consagração desta "desagregação da cultura indígena" foi justamente o convívio e interação 
dessas crianças indígenas com crianças brancas. Conforme Bezerra (2000) afirma, os jesuítas chegaram até a "importar crianças órfãs" no intuito de que estas e as crianças nativas pudessem ser educadas mutuamente. "Os missionários, com toda a boa vontade que a sua ideologia permitia, não tinham a intenção de erradicar o indígena, mas de educá-lo para que se fizesse um cristão.” (Bezerra, 2000, p. 14)

A educação jesuítica era baseada no Ratio Studiorum e fez parte do ensino colonial até meados do século XVIII, quando o seu método educacional passou a ser visto como ultrapassado em relação ao desenvolvimento intelectual que ocorria ao redor do mundo. É diante destes fatos e sobre a acusação de "ser um empecilho à conservação da unidade cristã e da sociedade civil" que a Companhia de Jesus é expulsa da Colônia portuguesa em 1759 por Sebastião José de Carvalho e Melo o Marquês de Pombal.

Nesses séculos em que a companhia passara no Brasil, possibilitou aos jesuítas uma grande ascensão econômica e importância social para a ordem. Tal enriquecimento da companhia não agradara muito o governo português que aspirava ser a única detentora deste poder. Tudo isso, juntamente com o momento de reformas que ocorria em Portugal no período denominado de fase pombalina, acarretará na expulsão da Companhia de Jesus de Portugal e, consequentemente, de suas colônias no ano de 1759. De acordo com Frota (2000, p. 164), adicionou a isso tudo a acusação de religiosos desta ordem terem participado do atentado em 1758 , contra o rei:

A ação de Pombal mostrou-se particularmente intensa contra os jesuítas, que não queriam aceitar a teoria do direito divino dos reis acusado de participarem do atentado contra o rei (03-09-1758) e de dificultarem a ação dos mercadores do Tratado de Madri, gerando a Guerra Guaranítica.

Esta fase tem início após a decadência economia em que Portugal se encontrava em decorrência da queda da mineração e, também, consequência da dominação espanhola sobre o território lusitano durante a União Ibérica que ocorrera de 1580 a 1640. Além do atraso cultural que estavam. Desse modo, toda essa conjuntura, aliada com as críticas de intelectuais portugueses influenciados por ideias iluministas que pediam por uma modernização, o Marquês de Pombal, como ministro do Estado coloca em prática tais reformas.

No entanto, passaram-se 13 anos até que isto acontecesse. Do momento em que a Companhia de Jesus foi expulsa do Brasil até estas reformas o sistema educacional passou por muitas dificuldades, a estrutura administrativa de ensino ficou desfeita e a simetria da ação pedagógica, a transição de um seriado para outro mais a graduação acabaram por serem substituídas "pela diversificação das disciplinas isoladas" de acordo com Romanelli (2014).

\subsection{A educação escolar durante o império (1808-1889)}

Em decorrência do cenário político em que a Europa encontrava-se — a chamada Grande Revolução- a Família Real portuguesa, sob a ameaça de ter seu território invadido pelas tropas de Napoleão Bonaparte, se viu obrigada a transferir seu governo para o Brasil. Ideia esta elaborada pelo Marquês de Pombal. “(...) em caso de salvaguardar a Monarquia em perigo, transferi-la para o Brasil." (Frota, 2000, p. 180).

Assim, em 22 de janeiro de 1808, D. João, a família Real e parte da Corte portuguesa chegavam às terras brasileiras. Com isso, e por aconselhamento de figuras importantes da época como o Marquês de Aguiar (D. Fernando José de Portugal e Castro) e o governador da capitania da Bahia, D. João de Saldanha da Gama Melo e Torres, o príncipe regente enfim, concorda com a ideia de abrir os portos para as nações amigas, pondo fim ao Pacto Colonial. O Desembarque havia sido na cidade de Salvador, porém a caravana real seguiu em direção ao Rio de Janeiro—capital da Colônia na época—e por lá se instalaram. Mas não antes de criar a Escola Médico-Cirúrgica em 18 de fevereiro de 1808, na capitania da Bahia. 
Dentro dessa nova realidade que vinha a ser o governo português instalado no Brasil, surge também a necessidade de reorganização na administração da colônia.

(...) com a nomeação dos titulares dos ministérios e o estabelecimento, no Rio de Janeiro, então capital, de quase todos os órgãos de administração pública e justiça, o que também ocorreu em algumas das capitanias. Provocou, por outro lado, o desenvolvimento da vida urbana de Vila Rica, Salvador, Recife e principalmente do Rio que, contando na época com cerca de 45.000 habitantes, recebe mais de 15.000 pessoas. (Ribeiro, 1998, p. 40)

Além disso, se faz necessário também, mudanças acerca do campo intelectual. Em virtude disto, é criada, ainda em 1808, a Imprensa Régia, a Biblioteca Pública—esta criada em 1810 e ofertada gratuitamente ao público apenas em 1814—o Jardim Botânico em 1810 e o Museu Nacional no ano de 1818. Em 1808 circula o primeiro jornal (A Gazeta do Rio), em 1812, a primeira revista (As Variações ou Ensaios de Literatura), em 1813, a primeira revista carioca—O Patriota. (Ribeiro, 1998, p. 40).

Com relação à educação neste período é importante ressaltar a criação de cursos e escolas profissionalizantes. Dentre elas, surgirão na Bahia os cursos de economia, agricultura, química e desenho técnico. O curso de agricultura tinha anexado a ele estudos relacionados à botânica e jardim botânico, enquanto o de química abrangia química industrial, geologia e mineralogia. "Em razão da revogação do Alvará de 1787, que fechara todas as fábricas, em 1812 é criada a escola de serralheiros, oficiais de lima e espingardeiros (MG)." (Ribeiro, 1998, p. 41).

Com a finalidade de formar oficiais, engenheiros civis e militares vão ser criada a Academia Real da Marinha e a Academia Real Militar — que ao longo do tempo sofreu alterações e passou a se chamar Escola Central (1858), depois Escola Politécnica, e atualmente é conhecida como Escola Nacional de Engenharia.

No Rio de Janeiro, serão criados os cursos de cirurgia e anatomia no ano de 1808, e no ano seguinte, o de medicina. O objetivo será a formação de cirurgiões para o Exército e a Marinha. Ainda no Rio de Janeiro, com o propósito de formar técnicos em economia, agricultura e indústria serão criados os cursos de laboratório de química (1812) e o curso de agricultura (1814). "Estes cursos representam a inauguração do nível superior de ensino no Brasil." (Ribeiro, 1998, p. 41).

Ribeiro (1998) ressalta que a palavra "curso" talvez não seja o termo que melhor defina o que ela vai chamar de "aulas avulsas" pois, não passavam justamente disto; aulas comuns realizadas para capacitar a elite aristocrática com a intenção destes assim preencher os cargos burocráticos e administrativos do governo. Além de suprir tantas outras necessidades que a sede da Coroa portuguesa precisava atender. A preocupação maior do Brasil naquele momento era profissionalizar aqueles que de certa forma pudessem ser úteis na administração, na saúde, na segurança ou qualquer outro setor necessário em uma metrópole.

É preciso lembrar também que tais reformas não foram feitas em todo o ensino. O primário, por exemplo, continuava tendo de apenas aprender a ler e escrever. E parecia não ter muita importância para o governo. Apenas quando começam a enxergar esse nível escolar como o meio de chegar ao secundário ou uma oportunidade de conseguir "pequenos cargos burocráticos" como explica Ribeiro, é que enfim o primário ganha mais importância.

No que diz respeito ao ensino secundário, foram criadas cadeiras de gramática latina, matemática superior em Pernambuco (1809), desenho e história em Vila Rica (1817), retórica e filosofia em Paracatu, Minas Gerais (1821) e duas cadeiras de inglês e uma de francês no Rio de Janeiro.

A Corte Portuguesa aqui permaneceu por um bom tempo, mas a população lusitana mostrava-se cada vez mais insatisfeita com a demora da volta do rei e de todos da família real e corte. O povo português a essa altura encontrava-se impaciente e em meio a tudo isso iniciou a Revolução Constitucionalista o que acabou resultando na volta do rei e toda a sua 
comitiva (1821). Membros dessa revolução posicionavam-se a favor da volta do Brasil as suas origens como colônia exploratória. Isso gera agitações, posições contrárias a isso que em 1822 tem como consequência a independência do Brasil.

A Constituição dessa nova nação é outorgada somente em 1824 e nela, é estabelecido que a instrução primária seria gratuita para todos os cidadãos.

Após a promulgação dessa Constituição foi sancionada a primeira Lei do Ensino Primário, promulgado em 15 de outubro de 1827, determinando que deviam ser criadas escolas de primeiras letras em todas as cidades, vilas e lugarejos e escolas de meninas nas cidades e vilas mais populosas (Godinho, 2014, p. 32).

A década de 1850 é vista como uma época de grandes feitos no que diz respeito à educação no Império. É em 1854 que é criado a Inspetoria Geral da Instrução Primária e Secundária do Município da Corte, com o propósito de fiscalizar e orientar o ensino público e privado. Segundo Ribeiro (2010), os motivos que levaram essas realizações no âmbito educacional se dão graças ao "crescimento econômico e a conciliação dos partidos (1853)". "Além disso, é apontada como sendo o resultado da atuação de homens considerados notáveis a exemplo de Couto Ferraz, Itaboray, Euzébio de Queiroz etc." (Ribeiro, 2010, p. 55).

A classe dominante, com privilégios, e por isso mesmo despreocupada com grandes transformações no sistema educacional que pudesse beneficiar as camadas mais baixas, deteve-se a mudanças superficiais, com um maior interesse para o nível superior. Porém, mesmo os cursos superiores não tinham muita profundidade, ao menos no que diz respeito aos conteúdos. A finalidade desses cursos era apenas profissionalizar.

Faltavam instituições que se dedicassem à pesquisa científica e aos estudos filosóficos metódicos. Esses foram desenvolvidos, na época, em grande parte pelos formados nos cursos jurídicos sob influência quase sempre francesa, numa linha eclética (Ribeiro, 2010, p. 56).

Os aspectos negativos encontrados nas escolas primárias e secundárias e as consequências que isso irá acarretar com os alunos oriundos desse ensino defasado, foram consequência da decisão do governo central de se isentar da obrigação de cuidar e fiscalizar desses níveis, que ficaram sob a responsabilidade das províncias. Nesse período, o que contava era o Status de Doutor, e por isso as escolas secundárias eram mais vistas como um preparatório para se chegar ao ensino superior, do que um sistema dedicado a prepara o cidadão.

\subsection{A educação escolar no século XX (até 1996)}

O século XX foi um século de grandes transformações políticas, econômicas e culturais, tudo isso, em período de tempo muito curto. Essas mudanças ocorreram em diversas áreas, inclusive na educação. No entanto, muitas dessas transformações tiveram início ainda no século anterior, com o fim da Monarquia e o início de uma nova forma de governo em 1889. A Constituição brasileira de 1891, criada após a instauração da República no Brasil, instituiu, entre outras coisas, a descentralização do ensino. Fazendo com que a União (poder federal) ficasse no encargo de criar universidades e instituições de ensino secundário nos Estados (antigas províncias), assim como também tinha o dever de promover a instrução secundária no Distrito Federal. Sobrando assim, a responsabilidade de criar e controlar o ensino primário e profissional para os estados. Romanelli (2019) destaca o quanto essa divisão de responsabilidades era desigual e refletia essencialmente na distância que ocorria entre a educação da classe dominante — que visava sempre o ensino secundário e superior-a educação do povo.

Enquanto isso, Godinho trata das mudanças que aconteceram no século XX e do quanto este notadamente é constituído na sua grande maioria de centros urbanos e como isso afeta os valores da época e os modifica, pois “O século XX diferencia-se, notadamente, por constituir-se de sociedades majoritariamente urbanas, de completa estrutura econômica, social, ocupacional, e principalmente, pela rapidez das mudanças de valores”. (Godinho, 2014, p 18). 
Tal ato acarretou em uma grande desorganização na elaboração e aplicação desse sistema educacional. Isso por que toda essa autonomia dada a ambas as delegações fazia com que existisse em todo país não apenas um sistema educacional, mas vários sistemas educacionais. Percebendo toda essa desorganização vigente no país, a Primeira República arriscou-se a reformar e solucionar os problemas na educação. Porém, conforme Romanelli (2014) ressalta tais reformas não obtiveram grande sucesso. A começar pela proposta da reforma Benjamin Constant que tentou substituir o currículo acadêmico por um enciclopédico, onde incluiria disciplinas científicas, além de organizar todo o sistema, incluindo as escolas primárias, normais, secundárias entre outras propostas. No entanto, suas ideias não foram colocadas em prática, pois, segundo Romanelli (2014), não havia a garantia de uma infraestrutura institucional para a implantação e execução do projeto e muito menos o "apoio político das elites" que viam nas ideias uma ameaça aos "valores e padrões da velha mentalidade aristocrático-rural” que a classe dominante passava para a juventude por meio do sistema educacional vigente.

Após o fracasso da reforma Benjamin Constant, outras vieram entre elas a Lei Orgânica Rivadávia Corrêa, ocorrida no Governo de Marechal Hermes da Fonseca. Esta também não teve sucesso.

(...) chegaram até a ocasionar um retrocesso na evolução do sistema, em virtude de facultar total liberdade e autonomia aos estabelecimentos e suprimir o caráter oficial do ensino, o que trouxe resultados desastrosos (Romanelli, 2014, p. 43-44).

A reforma posterior a esta foi a Carlos Maximiliano, que reformou o Colégio Pedro II, regulamentou o ingresso no ensino superior e, além disso, foi responsável por "reoficializar" o ensino. Em 1925, surgiu a Reforma Rocha Vaz. Sua principal missão era organizar a desestruturada educação do país.

Todas essas reformas, porém, não passaram de tentativas frustradas e, mesmo quando aplicadas, representaram o pensamento isolado e desordenado dos comandos políticos, o que estava muito longe de poder comparar-se a uma política nacional de educação (Romanelli, 2014, p. 44).

As taxas de analfabetismo da população eram muito altas, ao mesmo tempo em que começava a se perceber a importância da difusão do ensino primário. Políticos faziam campanhas a favor disso, reconhecendo essas necessidades sendo que alguns, não apenas queriam combater o analfabetismo, mas também estimular o nascimento de um novo sentimento por meio de um ensino cívico, o sentimento de patriotismo.

Com a sociedade brasileira se desenvolvendo em base urbano-comercial desde a segunda metade do século XIX, o analfabetismo passa a se constituir um problema, por que as técnicas de leitura e escrita vão se tornando instrumentos necessários à integração em tal contexto social (Ribeiro, 2010, p. 82).

Infelizmente não havia verba suficiente ou uma solução satisfatória para enfrentar isso. Ao contrário do que foi proposto, houve um aumento significativo no número de analfabetos da época. Não havia um sistema de registros eficientes que possam nos esclarecer a respeito das despesas que o governo poderia ter tido relacionadas à educação. Porém, Ribeiro conclui que certamente eram insuficientes para atender toda a população brasileira. "Para que se apreenda a característica básica da organização escolar neste período republicano, necessário se faz a compreensão da característica, também básica, da sociedade brasileira." (Ribeiro, 2010, p. 77).

Conforme Ribeiro relata, essa série de reformas ocorridas no sistema educacional durante o século XX, mostra que havia uma alternância entre a influência humanística clássica, a realista ou científica no ensino vigente na época.

Na reforma de Epitácio Pessoa foi retirada a biologia, a sociologia e a moral dos ensinos e incluído a lógica. Já a reforma Rivadávia teve influência positivista "tentando infundir um critério prático ao estudo das disciplinas, ampliando a 
aplicação do princípio de liberdade espiritual ao pregar a liberdade de ensino (desoficialização) e de frequência (...)”. (Ribeiro, 2010, p. 79-80).

Nesse período foi abolido o diploma e substituído por um "certificado de assistência", também foi transferido à responsabilidade dos exames de admissão ao ensino superior do secundário para as próprias universidades. O intuito era dar um novo significado ao secundário, que como foi mencionado antes, era visto apenas como um meio de chegar ao ensino superior. "Os resultados, no entanto, foram desastrosos. Daí as reformas de 1915 (Carlos Maximiliano) e de 1925 (Luís Alves/Rocha Vaz)." (Ribeiro, 2010, p. 80).

O momento que antecede a Revolução de 30 se dá, de acordo com Ribeiro (2010), graças "à existência de novas forças sociais", como consequência das modificações na condição econômica da época. Assim como na instauração da República, os militares lideravam o movimento que contestava o poder político vigente do momento. Isso culminou em uma série de revoltas “(...) como as do Forte de Copacabana, em 1922, a liderada por Isidoro Dias Lopes, em 1924, e a Coluna Prestes-1924 a 1927." (Ribeiro, 2010, p. 98).

Durante o período de 1930 a 1937 ocorreu no Brasil reformas no setor educacional realizadas pelo Ministro da Educação e Saúde Pública, Francisco Campos. Após essa fase da História tem início outra de igual importância, o Estado Novo. Nesse momento, de acordo com Romanelli (2014), a educação cada vez mais passa a ser vista como um "fator importante para o desenvolvimento". Essa fase, que tem início no ano de 1937 e se finda em 1946, foi:

(...) a da decretação das Leis Orgânicas do Ensino e da criação do Senai e do Senac. Representou, todavia, um intervalo nas lutas ideológicas em torno dos problemas educacionais (Romanelli, 2014, p. 129).

Já no período de tempo que corresponde de 1946 a 1961: “(...) se caracterizou pelo reinício das lutas ideológicas, em torno do projeto de Lei de Diretrizes e Bases.” (Romanelli, 2014, p. 129).

A Lei de Diretrizes e Bases da Educação Nacional nº 4.024 foi sancionada em dezembro de 1961 e organizava os níveis de ensino da seguinte forma: Ensino Primário, Ciclo Ginasial do Ensino Médio, Ciclo Colegial do Ensino Médio e Ensino Superior. Em 1964 ocorre no Brasil o golpe militar onde foi instaurado um regime ditatorial que perdurou por 21 anos. Durante esse período uma nova LDB foi sancionada em agosto de 1971.

A reforma educacional de 1971 completa a configuração do quadro da educação brasileira sendo que as mudanças nas diretrizes de ensino e currículo afetam diretamente o campo das ciências humanas, especialmente história e geografia. A partir daí, por pressão dos setores educacionais organizados, começa a haver revisões na legislação, e nas lutas que esboçaram um processo de redemocratização do país, a emergência de novas experiências e processos de mudanças nos projetos de currículo e ensino, buscando o redimensionamento da história ensinada em nível de escola fundamental (Guimarães, 2012, p. 13).

Após esse movimento de redemocratização foi promulgada a Constituição de 1988 na qual procurou reestabelecer à liberdade e os direitos aos cidadãos. É somente em 20 de dezembro de 1996 que foi então promulgado a LDB nº 9394 que vigora até os dias de hoje. Nessa nova LDB, a educação passou a ser dividida em Educação Básica (composta por Educação Infantil, Ensino Fundamental e Ensino Médio) e a Educação Superior.

\section{História Escolar e Ensino de História: histórias de uma disciplina ensinada no Brasil}

A história, enquanto componente curricular obrigatório começou a ser ensinada nas escolas brasileiras ainda na primeira metade do século XIX, logo após a independência do Brasil. Conforme tratamos acima neste texto e, predominou neste momento, e durante todo o século XIX, o ensino de uma história geral das civilizações de concepção eurocêntrica e com 
conteúdos programáticos determinados pelo Estado Imperial que deveriam ser seguidos por todas as escolas do país (Magalhães, 2003).

Ao longo do século XX, este modelo de disciplina escolar histórica passou a ser questionado. A criação da Revista Annales, fundada pelos historiadores franceses Marc Bloch e Lucien Febvre na Universidade de Estrasburgo (França), em 1929, alertava para o fato de que o modelo de produção historiográfico desenvolvido até aquele momento excluía outras dimensões da realidade humana que não apenas o político e a história dos líderes governamentais e Estados Nacionais. A partir daí, o movimento historiográfico conhecido como Escola do Annales criticava os textos e pesquisas históricas centrado nos fenômenos e personagens políticos e nos feitos dos governos e dos Estados. Fonseca (2003) afirma que até a primeira metade do século XX o ensino de história orientava-se por uma perspectiva tradicional, fundamentada no estudo dos grandes personagens da tradição política, preocupada com a sequência linear, progressiva e cronológica dos fatos e caracterizada pelo uso de materiais e metodologias de ensino mnemônicos e repetitivos.

A partir dos Annales, preocupou-se pela superação deste modelo de produção e disseminação historiográfica, denominado de história metódica ou positivista (Burke, 2012). A concepção defendida pelos Annales procura identificar como cultura toda a produção humana, considerando qualquer vestígio da passagem do homem como fonte documental das mais variadas tipologias para o trabalho de construção histórica, operação intelectual realizada pelo especialista, o historiador. A preocupação com as pessoas comuns e com as mentalidades coletivas, substitui ou complementa a narrativa com a análise das estruturas econômicas e sociais, criticando o modelo tradicional de produção histórica disseminado pela escola metódica (Burke, 2012; Cruz, 2007).

A partir dos anos 1970, influenciado por essas mudanças internacionais na produção historiográfica impulsionadas pelo movimento concebido com "os Annales" e também pela crescente influência das produções de orientação pautas no materialismo histórico-dialético, tanto como teoria sócio-política empregada na explicação da subordinação do Brasil aos países mais industrializados, como inspiração ideológica aos movimentos políticos de resistência ao regime político imposto pelo golpe militar de 1964, ocorreram algumas significativas mudanças nas concepções que passaram a orientar o ensino de história no Brasil.

Os governos militares procuraram implementar um controle extremamente hierarquizado e burocrático sobre o sistema educacional brasileiro. Gasparello (2001) chega a afirmar que nesse período não há, no âmbito sobretudo da escolarização regular, uma reflexão sobre o ensino de história que permita compreender as relações entre passado e presente, nem entre o global e o regional da experiência histórica do nosso país, faltando articulação entre as dimensões espaçotemporais da história brasileira com a história internacional.

Essa situação aponta para um ensino de história reprodutivista do modelo de sociedade hierarquizada e elitista herdado desde o período colonial, contribuindo para a manutenção da ordem social e contribuindo pouco para formação da cidadania e da criticidade dos educandos. Além disso, como ensino encadeado de fatos episódicos e narrativas de líderes políticos oficiais da história brasileira desde as séries iniciais até o ensino médio, este modelo de história escolar, expresso nos livros didáticos e nos programas escolares da época, encontrava-se muito distante dos debates e produções historiográficas acadêmicas, contribuindo para um distanciamento da relação entre o ensino de história e a história ensinada e produzida nas Universidades e Centros de Pesquisa.

Assim repito, sem que o quiséssemos (pois o discurso era de superação das dicotomias referentes ao ensino de História: ensino-pesquisa, Universidade-Escola, teoria-prática, bacharelado-licenciatura), constituiu-se uma fronteira indesejada mas efetiva. A lógica do sistema educacional (neste período), infelizmente, não obedece aos desejos dos grupos que militam nessa área e, tirando algumas exceções pontuais, à academia permaneceu o papel de pesquisar o ensino de História, enquanto à Escola coube o papel de 'praticá-la' (Cerri, 2005, p.9-10). 
Somente ao longo dos anos de 1980, houve claramente uma discussão dos elementos que compõe a pesquisa e a prática educacional no que dizem respeito ao ensino de história para as escolas brasileiras:

Repensamos, criticamos os diversos aspectos constitutivos da educação, a história e seu ensino: desde a política educacional, os currículos, a gestão, a escola, o ensino-aprendizagem, os professores, os alunos, até os pressupostos, os métodos, as fontes e os temas (Fonseca, 2003, p.31).

Bittencourt, nos chama a atenção para a luta de pesquisadores e professores de história - sobretudo no âmbito da influência dos professores e pesquisadores de história presentes em algumas importantes universidades brasileiras como a Universidade de São Paulo e a Universidade Federal Fluminense (Niterói-RJ), bem como pelo papel exercido pelos diversos encontros regionais e nacionais promovidos pela ANPUH (Associação Nacional de História, na nomenclatura adotada atualmente) desde o fim da década 1970 e durante os anos 1980 em abolir o ensino de Estudos Sociais e de disciplinas como Educação Moral e Cívica e Organização Social e Política Brasileira (OSPB) dos currículos escolares oficiais, disciplinas estas, que por sua vez, haviam sido implantadas pelos governos militares nos currículos da educação escolar brasileira (2011, p.15).

Esta autora ressalta, ainda, os embates pelo fim das licenciaturas curtas que formavam professores objetivando apenas a atuação docente da quinta a oitava série, nomeado à época de Primeiro Grau. O modelo educacional ainda vigente no início dos anos 1980 obedecia aos ditames da política educacional voltada para uma formação escolar tecnicista e irrefletida da realidade social, orientação impressa pelo regime militar. Esse modelo tecnicista caracterizava-se por fragmentar o currículo em planos de ensino e de curso, organizando em quadros sinópticos os objetivos, os conteúdos, os recursos e as estratégias didáticas e avaliação, normalmente um planejamento executado por especialistas anexos ou exteriores à escola, cabendo aos professores a sua execução. A crítica a este modelo e o desejo de superá-lo se alinhavam ao momento político de redemocratização e a democratização e ampla disseminação do ensino público (Bittencourt, 2006, p.23).

As críticas e posteriores mudanças concebidas no final dos anos 1980, denunciavam o eurocentrismo e a linearidade cronológica e progressiva do ensino de história, com a periodização submetida à dimensão política da trajetória percorrida pelo Brasil enquanto país, anexa ao ensino dos fatos e acontecimentos da história do mundo ocidental. Os conteúdos ensinados nas escolas brasileiras, de acordo com Bittencourt, obedeciam a lógica da apresentação dos modos de organização política e no estruturalismo econômico, que imobilizava as ações dos indivíduos em sociedade, principalmente aqueles pertencentes às periferias do mundo ocidental desenvolvido.

A década de 1990 apresentou significativas mudanças na educação escolar brasileira devido à promulgação da Lei $\mathrm{n}$. 9394 de dezembro de 1996, amplamente conhecida como a Lei de Diretrizes e Bases da Educação Nacional (LDB). No que nos interessa em particular, o ensino médio e o ensino de história neste nível de ensino, importa problematizar as Diretrizes Curriculares Nacionais vigentes neste período e os Parâmetros Curriculares Nacionais, implantados a partir de 1999.

Schimdt aponta que, a partir dessas orientações para a educação escolar, e em especial, para o ensino de história, podemos destacar três obras que esta autora considera como representativas dos indicativos da incorporação e proposição de novas perspectivas para a aprendizagem da história e que analisam a legislação pertinente e suas orientações: "Didática e Prática de ensino de História: experiências, reflexões e aprendizados” de Selva Guimarães Fonseca, publicado em 2003; "Ensino de História: fundamentos e métodos", escrito por Circe Maria F. Bittencourt (2019), editado pela primeira vez em 2004 e, "Ensinar História", publicado pelas professoras Maria Auxiliadora Schmidt e Marlene Cainelli também em 2004 (Schmidt, 2012, p.80).

Em geral, em todas essas obras há a concordância de que a proposta apresentada pelos Parâmetros Curriculares Nacionais para a história no ensino médio, neste momento do final dos anos 1990, assumiu uma concepção ampliada de 
currículo escolar em que os conteúdos são organizados por temas selecionados ou eixos temáticos, acreditando no potencial criativo e na iniciativa dos professores e das instituições escolares para planejarem e executarem as ações educativas.

Nestas décadas iniciais do século XXI cresce cada vez mais pressão para a amplitude e até a superação das fronteiras nacionais, no que se convencionou chamar de era da globalização. Por outro lado, crescem também movimentos nacionalistas e regionalistas em diferentes países, fazendo ressurgir antigos fantasmas sectários, xenófobos e extremistas. O ensino de história poderá caminhar para a direção da globalização dos conteúdos curriculares escolares, contribuindo para derrubar antigos contornos nacionais objetivando melhor dimensionar a relação entre os grupos humanos, suprimindo das práticas escolares conteúdos que possam estimular os antigos conflitos regionais, ou não, visto que tem havido usos justamente dos discursos historiográficos e da História escolar para reavivar e/ou fortalecer sentimentos e comportamentos das culturas locais e regionais.

Novas características e novos temas emergiram na última década em função do fim da experiência socialista soviética, da queda do Muro de Berlin, dos conflitos armados envolvendo os países do oriente islâmico e os Estados Unidos e dos atentados terroristas de 11 de setembro de 2001. Em vários países tem havido significativos mudanças no ensino de história na educação básica. Nos Estados Unidos, segundo Zarth, os novos referenciais curriculares nacionais representam um forte compromisso com o ensino de uma história em escala mundial e "pretendem encorajar o estudante a questionar e pesquisar sobre o passado humano, para comparar padrões de continuidade e mudança em diferentes partes do mundo e examinar as histórias e características particulares de povos e civilizações" (Zarth, 2004, p.114).

Por sua vez, a União Europeia tem estimulado projetos de pesquisa sobre as várias ciências humanas, consideradas de vital importância para a construção de uma identidade supranacional e, portanto, continental. Projetos como o "Eustory" organizado pela Fundação Körber (Alemanha) estudam o passado europeu "objetivando descobrir causas dos conflitos em nossas tradições", segundo o texto introdutório desta iniciativa, "e nas nossas imagens históricas e políticas e consolidar a consciência de ideias históricas em política" (Angvik \& Borries, 1997, p.7). Este projeto alemão teve ainda por meta "discutir os conceitos de História regional e nacional numa Europa unificada e num mundo globalizado (Zarth op cit.p.8).

No Brasil, durante os anos 2000 diversas pesquisas sobre o ensino de história (Silva \& Fonseca, 2007; Fonseca, 2003 \& 2009; Siman, 2004; Monteiro, 2007) apontavam para as suas peculiaridades, suas diferenças e dificuldades. Este campo de pesquisa ganhou muita força no Brasil, desde os anos 1990, apontando a emergência de grupos de pesquisadores universitários atuando em colaboração com professores da educação básica. As pesquisas procuraram se constituir em "uma postura política de produção de saberes, transgressão, emancipação e transformação social” (Silva \& Fonseca, op cit.p.37).

Cada vez mais pesquisadores e professores vem refletindo sobre as práticas de ensino, os modelos pedagógicos, os currículos, as tecnologias inovadoras de comunicação e informação e os métodos de ensino-aprendizagem, as inovações pedagógicas e as políticas educacionais de formação e qualificação docente, inicial, continuada e em serviço, assim como houve "o intercâmbio com pesquisadores e publicações de vários outros países, como Portugal, Espanha, Inglaterra e Estados Unidos em diversos eventos nacionais e internacionais organizados pelas diversas associações de pesquisa nesta área (Silva \& Fonseca, op cit.p.37-38).

Por isso, diversas são as questões que se impõe ao professor de história, identificada como uma profissão docente nada fácil, principalmente se o professor almejar,

formar alunos capazes de raciocinar historicamente, criticamente e com sensibilidade sobre a vida social, material e cultural das sociedades; se ele reconhece que o conhecimento histórico é fruto de operações cognitivas e sociais de ordem complexa que exigem dos alunos o desenvolvimento de capacidades que deem conta dessa complexidade e, ainda, se ele reconhece que a aprendizagem será mais significativa e afetiva se ele der conta de promover o trânsito entre os conhecimentos e as representações que os alunos já trazem e o 'novo' conhecimento a ser apropriado, 
Afirma Lana de Castro Siman (2004, p.81-82), do Instituto de Filosofia e Ciências Humanas da UFMG, partindo das considerações de um projeto sob sua orientação que versava sobre a formação da consciência histórica nos estudantes do ensino médio e o papel dos professores nesse processo, desenvolvido em escolas públicas de Belo Horizonte há alguns anos atrás.

O professor de história poderá conduzir seus alunos a questionamentos críticos ou poderá contribuir para a manutenção da ordem que marginaliza vários grupos humanos. Pois, a história e seu ensino escolar "exercem um papel decisivo na formação da consciência histórica dos alunos e da sociedade em geral, sobretudo quando identificamos uma sociedade marcada por diferenças e desigualdades” (Fonseca, 2003, p.38).

Por isso que o professor de história precisa se conscientizar do papel social que exerce diante dos alunos, “preocupando-se em ajudá-los a compreender e, - esperamos- a melhorar o mundo em que vivem” (Pinsky \& Pinsky, 2018: 22).

Sendo assim, ensino escolar de história na educação básica e, em especial no ensino médio, cumpre um papel preponderante na construção da identidade social e cultural dos estudantes enquanto cidadãos e sujeitos da sua cultura e da sua temporalidade histórica.

A legislação educacional brasileira, concebida e aplicada durante os anos 1990 e suas significativas diferenciações em relação às leis anteriores que regiam o sistema educacional brasileiro, buscaram atingir os objetivos básicos da educação escolar básica que consistia, neste momento da história brasileira, sobretudo em formar cidadãos para a vida em sociedade e, também, formar trabalhadores para as novas demandas do mercado profissional, segundo as exigências da economia global e altamente competitiva em uma sociedade multicultural e diversa. Esta legislação produzida neste período, inspirou-se sobremaneira em obras que abordam os saberes necessários para o século XXI conforme o proposto por Delors (1999).

Através do estudo das práticas pedagógicas em história no ensino médio acreditamos ser possível identificar a importância dos saberes e conhecimentos docentes que são vivenciados no cotidiano escolar, com ênfase a retradução que assumem os saberes curriculares e os saberes experienciais nesta prática. Pois esse cotidiano escolar rearticula esses saberes docentes diversos oriundos da formação inicial - constituída na licenciatura em História - e a continuada e acabam por adquirir uma configuração/reelaboração na realidade escolar regular e diária, sendo, portanto, os saberes que, de fato, determinam a ação docente, conforme afirmam Tardif et al.

Os saberes que orientam a prática não provêm das instituições de formação ou dos currículos, esses não se encontram sistematizados no quadro de doutrinas ou teorias: eles são saberes práticos, e não da prática: eles não se aplicam à prática para melhor conhecê-la, eles se integram a ela e são constituintes dela enquanto prática docente [...] são a cultura docente em ação (Tardif, Lessard \& Lahaye, 2001, p. 228).

\section{Considerações Finais}

Finalizamos estas reflexões, oriundas de pesquisa bibliográfica e documental, afirmando que o entendimento da prática pedagógica no ensino de história deve buscar atender as orientações curriculares formais contidas nos documentos que organizam o sistema educacional brasileiro. Obviamente ninguém prega a "ilegalidade" ou a "informalidade", não em sã consciência, sobretudo em se tratando de tão caro instrumento de consolidação e ampliação da democracia, bem como de preparação para a vida em sociedade como é a educação escolar. Também, as críticas ao modelo de pedagogia por competência ou voltada para a preparação ao mercado de trabalho, encontrados em alguns autores citados até aqui, não significam uma educação para formar "incompetentes" ou "ociosos". Refletem apenas que no entender desses autores - tornando difícil a não concordância com suas ideias - o desejo de que a educação não deva só ser transmissora e reprodutora de conhecimentos e informações alocados no patrimônio cultural acumulado pela humanidade por meio da cultura escolar, mas geradora e 
construtora de conhecimentos que realmente adquiram significado, importância e vitalidade para os educandos do ensino médio.

Dessa forma, portanto, assumimos o entendimento que o ensino e a aprendizagem da história constituem em uma gama enorme de experiências multidimensionais e polissêmicas que se reorganizam e se reestruturam no dia a dia, ano a ano, em cada singularidade vivida entre professores e alunos, na dinâmica escolar, moldando práticas sob o enfoque de saberes plurais ressignificados. Objetivou-se, assim, a partir das discussões travadas ao longo deste artigo, a partir de uma investigação qualitativa pelo método bibliográfico, contribuir para descortinar cada vez mais esta temática, pois descrevendo trajetórias percorridas e contextos históricos diversos, da colônia ao fim do século XX, pode-se ampliar reflexões, e sobretudo, pode-se fomentar um debate cada vez mais profícuo em torno do Ensino de História e da História Escolar, uma vez que,

[A História Escolar e seu ensino tem] múltiplas relações com as várias dimensões da sociedade, sua posição como instrumento científico, político, cultural para diferentes grupos, indica a riqueza de possibilidades para seu estudo e o quanto ainda há para investigar (Fonseca, 2004, 28).

Finalmente, as discussões aqui empreendidas apontam para a necessidade de realização de novos e futuros trabalhos, novas e futuras pesquisas, investigações e interpretações, constantemente em diálogo com novas categorias teóricas assim como por meio de tantos outros inovadores métodos de investigação e interpretação sobre o Ensino de História e a História da História enquanto disciplina escolar. E, assim, ao demandar a produção de outros trabalhos, certamente, permaneceremos afinados com esta discussão, participando, contribuindo, desenvolvendo ativamente este empreendimento, haja vista a importância de cada vez mais incrementar e manter atualizado o debate relacionado às temáticas abordadas.

\section{Referências}

Abud, K. M. (2007). A história nossa de cada dia: saber escolar e saber acadêmico em sala de aula. In: Monteiro, A. M. et. al. (orgs.). Ensino de História: sujeitos, saberes e práticas. Mauad X. 107-118.

Abud, K. M., (2001). Currículos de História e Políticas Públicas: Os Programas de História do Brasil na Escola Secundária. IN: Bittencourt, C. O Saber Histórico na Sala de Aula. Contexto.

Angvik, M., \& Borries, B. (1997). Youth and History: A comparative european survey on historical consciousness and political attitudes among adolescents. Körber-stiftung.

Bezerra, A. C. S., \& Silva, H. (2000) De uma escola 'para o indio' para uma escola indígena: ideias sobre a educação escolar indígena na história do brasil. Curso de Especialização em Programação do Ensino de História. Universidade de Pernambuco. Monografia.

Bittencourt, C. (2019). Ensino de História: Fundamentos e Métodos. Cortez.

Bittencourt. (2011). O saber histórico na sala de aula. São Paulo: Contexto. 11-27.

Brasil. MEC. (2002). Secretaria de Educação Média e Tecnológica. Parâmetros Curriculares Nacionais - Ensino Médio. SEMTEC/MEC, 1999.

Brasil. (2002). PCN+Ensino Médio - Orientações Complementares aos PCN's. SEMTEC/MEC.

Brasil. (1996). Lei de Diretrizes e Bases da Educação Nacional (Lei n. 9394 de 1996). MEC.

Brasil. (2010). Conselho Nacional de Educação. Câmara de Educação Básica. Resolução n. 04 de 13 de julho de 2010 (Diretrizes Curriculares Nacionais Gerais para a Educação Básica). MEC/CNE.

Borges, C. M., \& Tardif, M. (2001). Dossiê: Os saberes dos docentes e sua formação. Educação e Sociedade. 22(74). 11-26.

Burke, P. (2012). História e Teoria Social. EDUNESP.

Candau, V. M. (2002). Didática, currículo e saberes escolares. DP e A.

Cerri, L. F. (2004/2005). Ensino de História: Fronteiras interdisciplinares, avanços e problemas. Cadernos de História 12/13(1). 7-22. Universidade Federal de Uberlândia.

Cerri, L. F. (2007). Uma proposta de mapa do tempo para artesãos de mapas do tempo: história do ensino de história e didática da história. IN: Monteiro, A. M., Gasparello, A. M., \& Magalhães, M. de S. Ensino de História: sujeitos, saberes e práticas. Mauad X-FAPERJ. 59-72. 
Research, Society and Development, v. 10, n. 8, e19510817344, 2021

(CC BY 4.0) | ISSN 2525-3409 | DOI: http://dx.doi.org/10.33448/rsd-v10i8.17344

Cruz, M. B. A. (2020). O ensino de história no contexto das transições paradigmáticas da História e da Educação. IN: NIKITIUK, S. L. (orga.). Repensando o Ensino de História. Cortez. 67-76

Cunha, M. I. da (2004). O Bom Professor e sua prática. Papirus.

Delors, J. (1999). Os quatro pilares da educação In: Educação: um tesouro a descobrir. Cortez.

Delors, J. (2012). Pedagogia e Prática docente. Cortez.

Fonseca, S. G. (2003). Didática e Prática de Ensino de História. Papirus.

Fonseca, S. C. (2012). Caminhos da História Ensinada. Papirus.

Fonseca, T. N. L. (2004). História \& Ensino de História. Autêntica.

Frota, G. A. (1996). História do Brasil- Colônia. Biblioteca do Exército Ed.

Gasparello, A. M. (2001). Construindo um novo currículo de história. IN: NIKITIUK, S. L. (orga.) Repensando o Ensino de História. 77-92.

Gimeno Sacristán, J.(1995). Consciência e acção sobre a prática como libertação profissional dos professores. In: Nóvoa, A. Profissão Professor. Porto Ed., 1995. 63-92.

Gimeno Sacristán, J., \& Pérez Gómez, A. I. (1995). Compreender y transformar la enseñanza. Ediciones Morata.

Godinho, M. G. (2014). Políticas Públicas e Organização da Educação Básica. SESES.

Lakatos, E. M., \& Marconi, M. A. (2019) Fundamentos de Metodologia Científica. Atlas.

Lüdke, M. \& Andre, M. E. D. A. (2013). Pesquisas em educação: uma abordagem qualitativa. E.P.U

Karnal, L. (2018). História na sala de aula: conceitos, práticas e propostas. Contexto.

Magalhães Junior, A. G. M., Lima, J. M. C., \& Freire, V. C. C. (2015). Ensinando História no Brasil: Trajetórias e Percursos. In: Magalhães Junior, A. G. M., \& Araújo, F. M. L. (orgs.). Ensino \& Linguagens da História. EdUECE.

Morais, M. V. (2018). História Integrada. In: Pinsky, C. B. Novos Temas nas Aulas de História. Contexto.

Monteiro, A. M. (2007). Professores de História: entre saberes e práticas. Mauad X.

Monteiro, R. G. (2009). O bom professor pela ótica do aluno do ensino médio na escola pública e privada. PUC-PR: Programa de Pós-graduação em Educação. Dissertação de Mestrado.

Oliveira, M. D., \& Cainelli, M. (orgas.) (2008). Ensino de História: múltiplos ensinos em múltiplos espaços. EDUFRN.

Pinsky, J. \& Pinsky, C. B. (2018). O que e como ensinar: por uma história prazerosa e consequente. In: Karnal, L. (org.). História na sala de aula. Contexto. 17-36.

Reis, J. C. (2006). História \& Teoria: Historicismo, Modernidade, Temporalidade e Verdade. Editora FGV.

Ribeiro, M. L. S. (2010). História da Educação Brasileira: a organização escolar. Autores Associados.

Romanelli, O. O. (2014). História da Educação no Brasil: (1930-1973). Vozes.

Schmidt, M. A. M. (2012). História do ensino de História no Brasil: uma proposta de periodização. História da Educação. 16(37). 73-91.

Severino, A. J. (2016). Metodologia do Trabalho Científico. Cortez.

Silva, M., \& Fonseca, S. G. (2007). Ensinar História no século XXI: Em busca do tempo entendido. Papirus.

Siman, L. M. C. (2004). O papel dos mediadores culturais e da ação mediadora do Professor no processo de construção do conhecimento histórico pelos alunos. IN: Zarth, P. A. et al. (orgs.). Ensino de História e Educação. Edunijuí. 81-107.

Tardif, M., Lessard, C., \& Lahaye, L. (2001). Esboço de uma problemática do saber docente. Teoria e Educação. Porto Alegre, 4. 215-234.

Zarth, P. A., et al. (orgs.). (2004). Ensino de História e Educação. Edunijuí.

Wehling, A., \& Wehling, M. J. C. (1994). Formação do Brasil Colonial. Nova Fronteira. 